\title{
Study of acupuncture for low back pain in recent 20 years: a bibliometric analysis via CiteSpace
}

\author{
Yu-Dan Liangl,* \\ Ying $\mathrm{Li}^{1, *}$ \\ Jian Zhao ${ }^{2}$ \\ Xiao-Yin Wang ${ }^{3}$ \\ Hui-Zheng Zhu' \\ Xiu-Hua Chen' \\ 'The Second Clinical Medical \\ College of Guangzhou University \\ of Chinese Medicine, Guangzhou, \\ ${ }^{2}$ Longgang District People's Hospital \\ of Shenzhen, Shenzhen, ${ }^{3}$ Guangdong \\ Second Traditional Chinese Medicine \\ Hospital, Guangzhou, People's \\ Republic of China
}

*These authors contributed equally to this work
Correspondence: Xiu-Hua Chen The Second Clinical Medical College of Guangzhou University of Chinese Medicine, No III Dade Road, Yuexiu District, Guangzhou 510210, People's Republic of China

Tel +862087887233

Email xiuhuachen0332@163.com
This article was published in the following Dove Press journal:

Journal of Pain Research

24 April 2017

Number of times this article has been viewed

Background: Acupuncture has been applied to relieve low back pain (LBP) in many countries. However, a bibliometric analysis of the global use of acupuncture for LBP is rare.

Objective: The aim of this study was to demonstrate the state of the art and trends concerning the global use of acupuncture for LBP in recent 20 years.

Methods: Literature relating to acupuncture for LBP from 1997 to 2016 was retrieved from Web of Science. CiteSpace was used to analyze country/institution, cited journals, authors/cited authors, cited references, and keywords. An analysis of counts and centrality was used to reveal publication outputs, countries/institutions, core journals, active authors, foundation references, hot topics, and frontiers.

Results: A total of 958 references were obtained, and the total number of publications continually increased over the investigated period. Journal articles (662) were the most frequently occurring document type. The most productive country and institution in this field was the USA (342) and Harvard University (47), respectively. The JAltern Complem Med (69) was the most productive journal, and Pain (636) was the most cocited journal, which reflected the nature of the research. The Haake's (2007) article (cocitation counts: 130) and the Cherkin's (2001) article (centrality: 0.59 ) were the most representative and symbolic references, with the highest cocitation number and centrality, respectively. Cherkin was the most influential author, with the highest number of publications of 25 and a cocitation number of 226. The four hot topics in acupuncture for LBP were research method, evaluation, economy, and comprehensive therapy. The three frontier topics were intervention, test reliability, and prevalence.

Conclusion: This study provides an insight into acupuncture for LBP and valuable information for acupuncture researchers to identify new perspectives on potential collaborators and cooperative institutions, hot topics, and research frontiers.

Keywords: acupuncture, low back pain, bibliometric analysis, CiteSpace, cocitation

\section{Background}

Low back pain (LBP) is a common and major problem, with a high prevalence among females and the elderly. ${ }^{1}$ The prevalence among workers was found to have reached $25.7 \%$ in the USA. ${ }^{2}$ Nonspecific LBP is one of the main problems contributing to the disease burden worldwide. ${ }^{3}$ Acute LBP persists for $<4$ weeks, chronic LBP persists for $>12$ weeks, and subacute LBP is another subtype. LBP not only affects daily activities and the quality of life but also increases health care expenditure. In 1998, the total health care expenditure in the USA incurred as a result of back pain reached 90.7 billion dollars, and from 1997 to 2005, health care costs associated with spine-related disease (including back pain) increased substantially. ${ }^{4,5}$ 
Acupuncture for LBP is still a topic under investigation. An evaluation from the Mayo Clinic indicated that complementary approaches, including acupuncture, are used to manage back pain. ${ }^{6}$ A survey reported that $24 \%$ of UK physiotherapists would like to manage pregnancy-related LBP using acupuncture. ${ }^{7} \mathrm{~A}$ multicenter randomized controlled clinical trial suggested that motion style acupuncture could relieve pain immediately and had positive effects on functional recovery. ${ }^{8}$ Another study suggested that the mechanism of acupuncture in chronic LBP might be modulation of the default mode network. ${ }^{9}$

Bibliometrics is a statistical analysis and quantitative tool to study publications. Bibliometric methods have been applied in many research fields to evaluate patterns in countries, institutions, journals, authors, and keywords associated with specific publication types. ${ }^{10-12}$ Han et al and More et al performed a global bibliometric analysis from 1991 to 2009 and from 2000 to 2014 based on the Web of Science database to evaluate the development trends and future research direction of acupuncture. ${ }^{13,14}$ However, a specific bibliometric analysis of the global use of acupuncture for LBP has not yet been performed. CiteSpace software was invented in early 2004 by Professor Chaomei Chen. It is characterized by cooccurrence network maps of authors, keywords, institutions, countries, and subject categories and cocitation networks of cited authors, cited references, and cited journals. ${ }^{15,16}$

In this study, to analyze the research situation and trends concerning the global use of acupuncture for LBP within the past 20 years, CiteSpace was applied to make a bibliometric analysis of related references derived from Science Citation Index-Expanded (SCI-E) of the Web of Science database from 1997 to 2016.

\section{Methods}

\section{Data acquisition}

Data retrieval strategy: topic: (low back pain) AND topic: (acupuncture) index $=$ SCI-EXPANDED time span $=1997-$ 2016 (retrieved date November 28, 2016). No document type, language, or data category was restricted. A total of 958 references were obtained.

\section{Analysis tool}

CiteSpace was used to perform a bibliometric analysis. Visualization knowledge maps consist of nodes and links. Different nodes in a map represent elements such as a cited reference, institution, author, and country, and links between nodes represent relationships of collaboration/cooccurrence or cocitations. The color of nodes and lines represents different years. The purple round represents centrality. Nodes with high centrality are usually regarded as turning points or pivotal points in a field..$^{15,17,18}$

The parameters of CiteSpace were as follows: time slicing (1997-2016), years per slice (1), term source (all selection), node type (choose one at a time), selection criteria (30), pruning (pathfinder), and visualization (cluster view-static, show merged network).

\section{Results and discussion Analysis of publication outputs}

The total number of publications increased over the studied period but with some fluctuations. As shown in Figure 1, the studied period could be divided into the following three stages: the first stage ran from 1997 to 2001, the second stage ran from 2002 to 2010, and the third stage ran from 2011 to 2016. The period from 2002 to 2010 was a rapid development period, and the publication outputs were 16 references in 2002, rising to 86 references in 2010 . The growth rate of the publication outputs decreased from 2011 to 2012, and it did not recover until 2013. However, the total number of publications was higher in the third stage (464 references) compared with the other stages (71 and 423 in the first and second stages, respectively). These results indicate that acupuncture, as a complementary and alternative treatment method for LBP, is receiving increased attention and more acupuncture research is being performed.

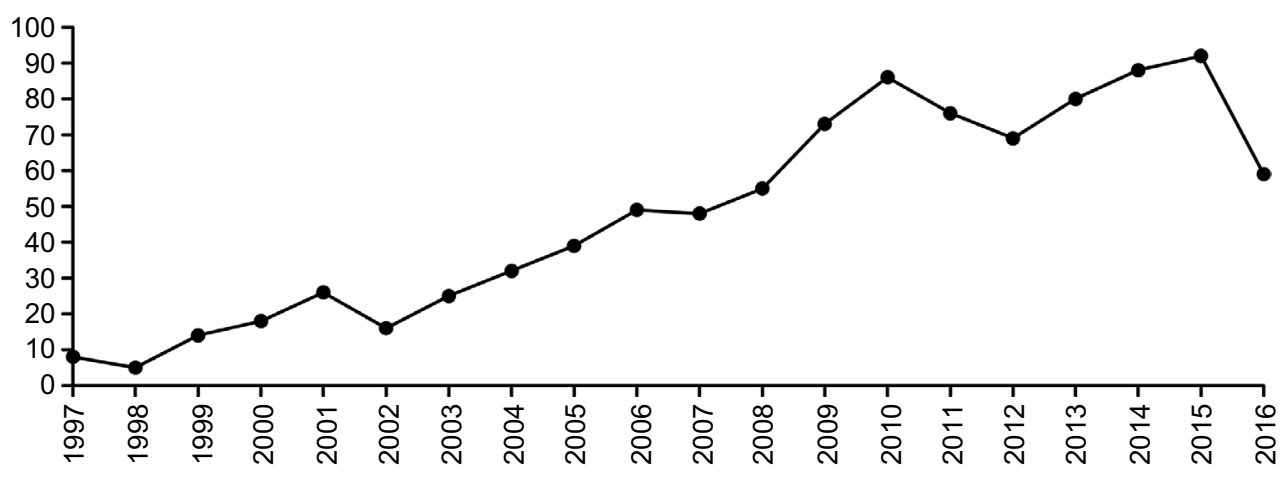

Figure I The number of acupuncture for LBP publications indexed by SCI-E from 1997 to 2016.

Abbreviations: LBP, low back pain; SCI-E, Science Citation Index-Expanded. 


\section{Analysis of document type}

There were eight document types identified in a total of 958 references. Journal articles (662) are the most frequently used document type, accounting for $69.10 \%$ of the total references. They are followed by reviews $(202,21.09 \%)$ and editorial material $(38,3.97 \%$; Table 1). The most cited article was "Survey of chronic pain in Europe: prevalence, impact on daily life, and treatment". In that article, Breivik reported that two-thirds of respondents who suffered from chronic pain (including LBP) used alternative treatments, such as acupuncture (13\%). ${ }^{19}$ The most cited review was "Diagnosis and treatment of low back pain: a joint clinical practice guideline from the American College of Physicians and the American Pain Society" in 2007, which made a weak recommendation of acupuncture for chronic or subacute LBP. ${ }^{20}$ "A clinical practice guideline from the American College of Physicians" recommends that for patients with LBP, clinicians and patients should initially select nonpharmacological treatments, such as exercise, multidisciplinary rehabilitation, acupuncture, and mindfulness-based stress reduction (moderate-quality evidence). ${ }^{21}$

\section{Analysis of country and institution}

Generating a country map using CiteSpace resulted in 47 nodes and 43 links (Figure 2). The 958 references were published by research groups in 47 countries. The top five countries were the USA, England, Germany, People's Republic of China, and South Korea (Table 2). The top five countries in terms of centrality (purple round) were Canada (0.49), Finland (0.45), Brazil (0.36), Norway (0.34), and Israel (0.34). An analysis in terms of publication and centrality indicated that the USA, England, and Canada were the main research powers in acupuncture for LBP research, and the strongest collaborations were identified between Canada, Japan, Australia, China, Brazil, and the Netherlands.

Table I Document types for documents referencing acupuncture for LBPa

\begin{tabular}{|c|c|c|c|c|c|}
\hline Ranking & Type & Counts (\%) & Ranking & Type & Counts (\%) \\
\hline I & Article & $662(69.10)$ & 5 & $\begin{array}{l}\text { Proceedings } \\
\text { paper }\end{array}$ & $13(1.36)$ \\
\hline 2 & Review & $202(21.09)$ & 6 & $\begin{array}{l}\text { Meeting } \\
\text { abstract }\end{array}$ & $8(0.84)$ \\
\hline 3 & $\begin{array}{l}\text { Editorial } \\
\text { material }\end{array}$ & 38 (3.97) & 7 & Correction & $5(0.52)$ \\
\hline 4 & Letter & $28(2.92)$ & 8 & New item & $2(0.2 \mathrm{I})$ \\
\hline
\end{tabular}

Notes: ${ }^{\mathrm{T}}$ The data has been taken from the publication year to retrieved date (November 26, 2016).

Abbreviation: LBP, low back pain.
Generating an institution map using CiteSpace resulted in 335 nodes and 347 links (Figure 3). The 958 publications were distributed among 335 research institutions. The top five institutions were Harvard University, University of Maryland, Korea Institute of Oriental Medicine, University of York, and Kyung Hee University (Table 2). The top five institutions in terms of centrality were University of Maryland (0.15), Group Health Cooperative Puget Sound (0.15), University of Washington (0.08), Acupuncture Res Grp (0.08), and University of York (0.06). Analysis in terms of publication and centrality indicated that the main research institutions were Harvard University (USA) and University of Maryland (USA), and the strongest collaborations were identified between University of Maryland, McMaster University, Group Health Cooperative Puget Sound, and Charite University Medical Center.

\section{Analysis of journals and cocited journals}

"Core journals" are important journals with high publication and cocitation counts. Knowledge maps can provide information of professional journals in a field.

Table 3 shows the top 10 scholarly journals that published articles related to acupuncture for LBP. They are professional

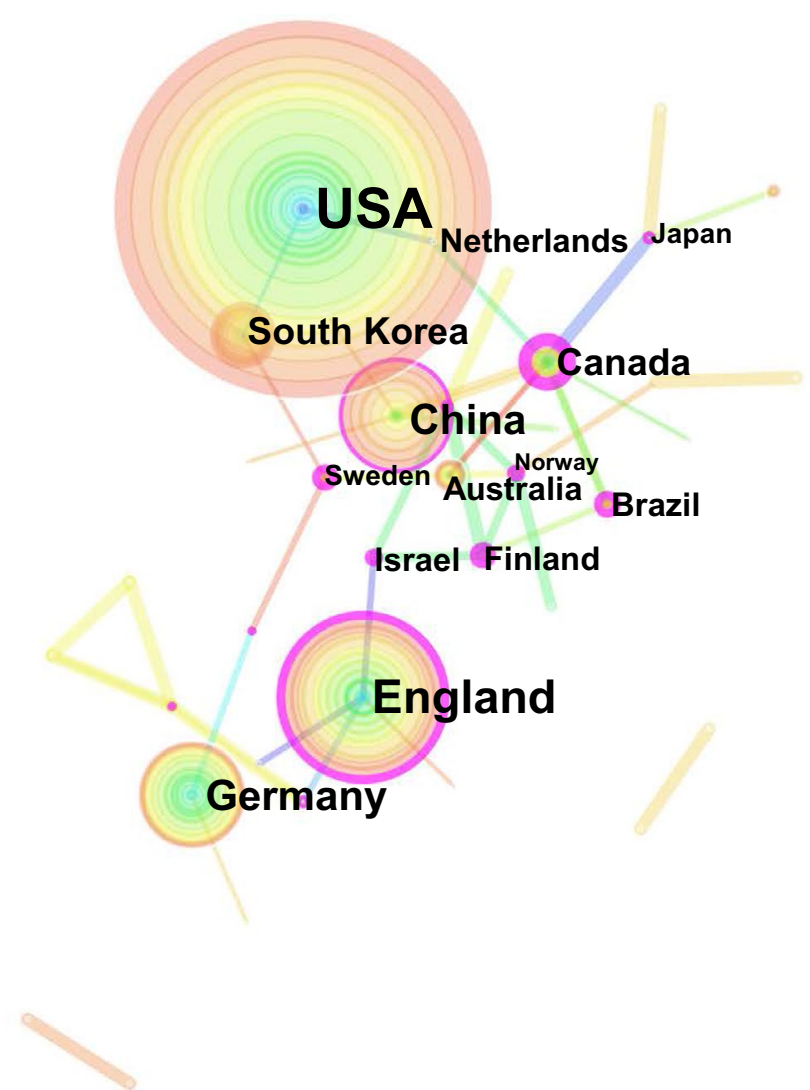

Figure 2 Map of countries researching acupuncture for LBP from 1997 to 2016. Abbreviation: LBP, low back pain. 
Table 2 Top 10 prolific countries and institutions researching acupuncture for LBPa

\begin{tabular}{llllll}
\hline Ranking & Publications & Country & Ranking & Publications & Institution \\
\hline 1 & 342 & USA & 1 & 47 & Harvard University \\
2 & 149 & England & 2 & 34 & University of Maryland \\
3 & 118 & Germany & 3 & 29 & Korea Institute of Oriental Medicine \\
4 & 109 & China & 4 & 29 & University of York \\
5 & 74 & South Korea & 5 & 27 & Kyung Hee University \\
6 & 64 & Canada & 6 & 26 & University of Exeter \\
7 & 58 & Australia & 7 & 21 & Pusan National University \\
8 & 31 & Netherlands & 8 & 21 & University of North Carolina \\
9 & 28 & Sweden & 9 & 21 & University of Washington \\
10 & 27 & Japan & 10 & 20 & University of Southampton \\
\hline
\end{tabular}

Notes: ${ }^{a}$ The data has been taken from the publication year to retrieved date (November 26, 2016).

Abbreviation: LBP, low back pain.

Figure 3 Map of institutions researching acupuncture for LBP from 1997 to 2016.

Abbreviations: LBP, low back pain; Univ, university; Korea Inst Oriental Med, Korea Institute of Oriental Medicine.

journals in this field. Among them, the average impact factor (IF) is 2.751. However, there were some articles that were highly cited, such as an article in J Altern Complem Med that was cited 90 times, and reported a nationally representative cross-sectional survey of acupuncture use in the USA. Among recent users, the most typical treatment regimen was 2-4 treatments $(34.5 \%)$, with musculoskeletal complaints being the most frequently reported condition, followed by back pain $(34.0 \%) .{ }^{22}$ In addition, there were a few articles published in high-IF journals such as the Brit Med J (IF =17.215) and the Ann Int Med (IF =16.593). For example, Ratcliffe J performed a cost-effectiveness analysis to evaluate acupuncture in the 
Table 3 Top 10 scholarly journals related to acupuncture for LBP research

\begin{tabular}{|c|c|c|c|c|c|c|c|}
\hline Ranking & Publications & Journal & $\begin{array}{l}\text { IF (Q) } \\
(20 \mid 6)\end{array}$ & Ranking & Publications & Journal & $\begin{array}{l}\text { IF (Q) } \\
(20 \mid 6)\end{array}$ \\
\hline I & 69 & J Altern Complem Med & $1.395(2)$ & 6 & 30 & Spine & $2.439(I)$ \\
\hline 2 & 61 & Evid-Based Compl Alt & $1.931(2)$ & 7 & 27 & BMC Complem Altern M & $1.987(\mathrm{I})$ \\
\hline 3 & 47 & Acupunct Med & $1.592(2)$ & 8 & 25 & Cochrane Db Syst Rev & $6.103(1)$ \\
\hline 4 & 36 & Complement Ther Med & $1.935(1)$ & 9 & 22 & Clin J of Pain & $2.712(2)$ \\
\hline 5 & 31 & Pain & $5.557(1)$ & 10 & 18 & Trials & $1.859(3)$ \\
\hline
\end{tabular}

Note: alF and $Q$ in category according to Journal Citation Reports (2015).

Abbreviations: IF, impact factor; LBP, low back pain; Q, quartile.

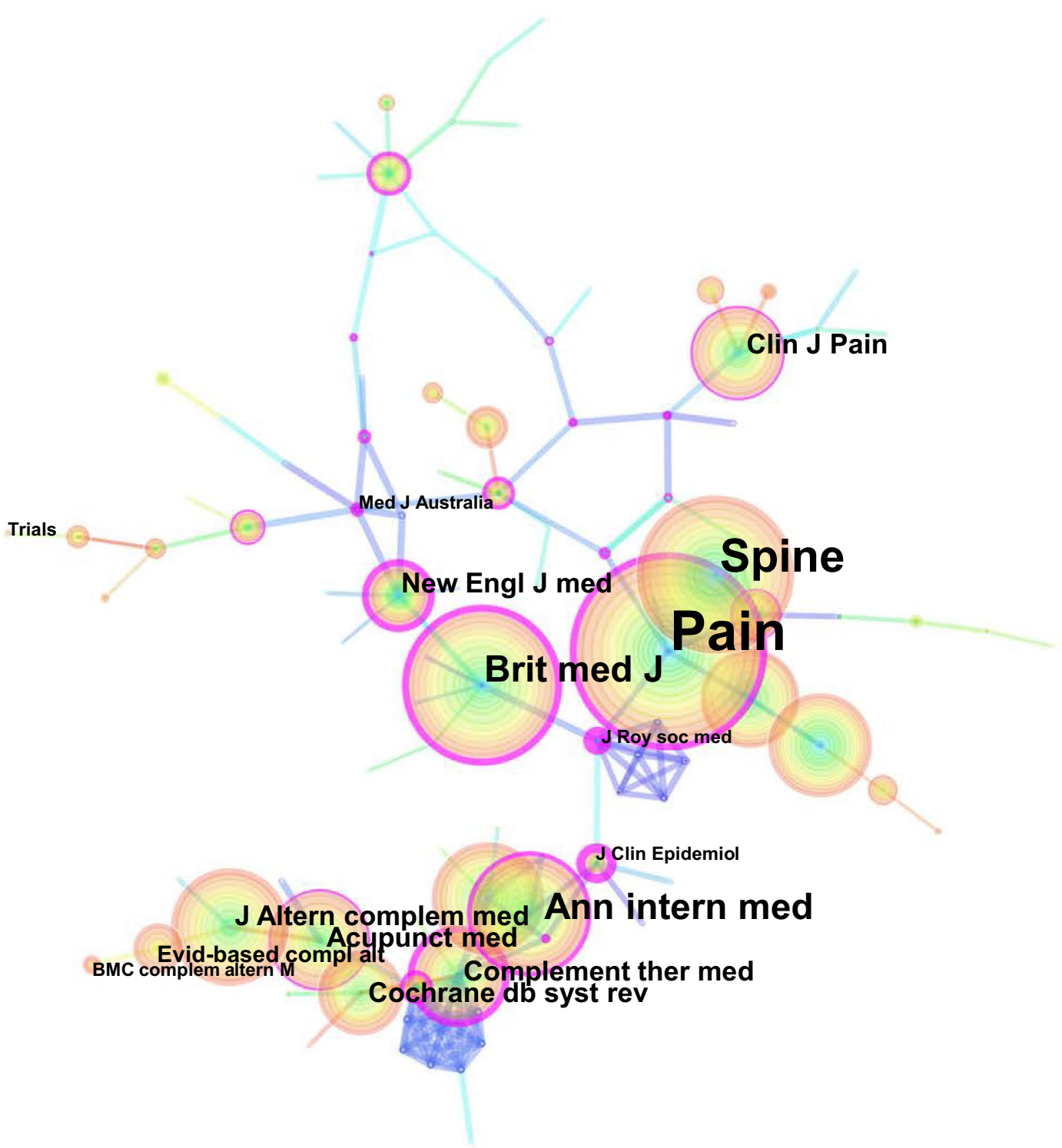

Figure 4 Journal cocitation map related to acupuncture for LBP research from 1997 to 2016.

Abbreviation: LBP, low back pain.

management of persistent nonspecific LBP. Acupuncture care for LBP had a $>90 \%$ chance of being cost-effective at a $£ 20,000$ cost per threshold, and it seems to be cost-effective in the longer term. ${ }^{23,24}$ The quartile category was commonly 1 and 2. There were five journals (ranks 1,2,3,4, and 7) belonging to the Integrative \& Complementary Medicine category.
Generating a cocitation journal map using CiteSpace resulted in 115 nodes and 160 links (Figure 4). From Table 4 and Figure 4, the top five cocited journals were Pain, Spine, Brit Med J, Ann Intern Med, and J Altern Complem $M e d$, and the top five in terms of centrality were $J$ Roy Soc Med, J Clin Epidemiol, Pain, Complement Ther Med, and 
Table 4 Top five cocited journals and centrality related to acupuncture for LBP research ${ }^{\mathrm{a}}$

\begin{tabular}{lllll}
\hline Ranking & Cocitation counts & Cited journal & Centrality & Cocited journal \\
\hline $\mathrm{I}$ & 636 & Pain & $0.8 \mathrm{I}$ & J Roy Soc Med \\
2 & 556 & Spine & 0.67 & J Clin Epidemiol \\
3 & 504 & Brit Med J & 0.54 & Pain \\
4 & 424 & Ann Intern Med & 0.52 & Complement Ther Med \\
5 & 416 & J Altern Complem Med & 0.46 & Med J Australia \\
\hline
\end{tabular}

Note: ${ }^{\top}$ The data has been taken from the publication year to retrieved date (November 26,2016 ).

Abbreviation: LBP, low back pain.

\section{Sherman KJ}

\section{Cherkin DC}

Kaptchuk TJ

Lao LX

Berman B

MacPherson $\mathrm{Her}_{\mathrm{B}}$

Berman BM

Ernst E

Witt CM

Willich SN

Ludtke R

Jena S

\section{Lee MS}

Shin BC

\section{Linde $\mathrm{K}$}

Figure 5 A coauthor map related to acupuncture for LBP research from 1997 to 2016.

Abbreviation: LBP, low back pain.

Med $J$ Australia. In an analysis of publication and cocitation counts and centrality, the journal Pain was identified as the core journal in acupuncture for the LBP research field, and its published articles reflect the fundamentals of the research field.

\section{Analysis of author and cocited author}

Knowledge maps can provide information on influential research groups and potential collaborators and can help researchers to establish collaborations.
Generating a coauthor map using CiteSpace resulted in 428 nodes and 600 links (Figure 5). The 958 publications were published by 428 research authors. Table 5 shows the top 10 authors who have published articles related to acupuncture for LBP. They are active and professional authors in this field. MacPherson is based at the University of York (England), and studies acupuncture for LBP in terms of traditional diagnosis and treatment, cost-effectiveness analysis, the effect of treatment course, and the willingness of patients to try the treatment. One of his studies deals with the treatment reactions 
of patients in an LBP trial and showed that relaxation was commonly reported $(84 \%, n=112)$, which was significantly associated with willingness to try acupuncture again. ${ }^{23,25-28}$ There were some collaborations between Cherkin, Sherman, Kaptchuk, Lao, and Berman and between Witt, Berman, Ludtke, Willich, and Jena. However, the centrality for such collaborations was 0 , suggesting that collaboration between research authors is not yet sufficient.

Generating an author cocitation map resulted in 178 nodes and 285 links (Figure 6). From Table 6 and Figure 6, the top five cocited authors were Cherkin, Ernst, Furlan, Linde, and
Brinkhaus and the top five authors in terms of centrality were Linde, Ernst, Han, Fox, and Fisher. An analysis in terms of cocitation counts and centrality revealed that Cherkin, Ernst, and Linde were "core strength" researchers and their research had an important influence on the field. Cherkin is based at the University of Washington (USA) and studies acupuncture for LBP in terms of efficacy for chronic LBP, the association of patient expectations and treatment effects, comparison between acupuncture and usual care and simulated acupuncture, the diagnosis and treatment by acupuncturists, and comparisons between acupuncture, therapeutic massage,

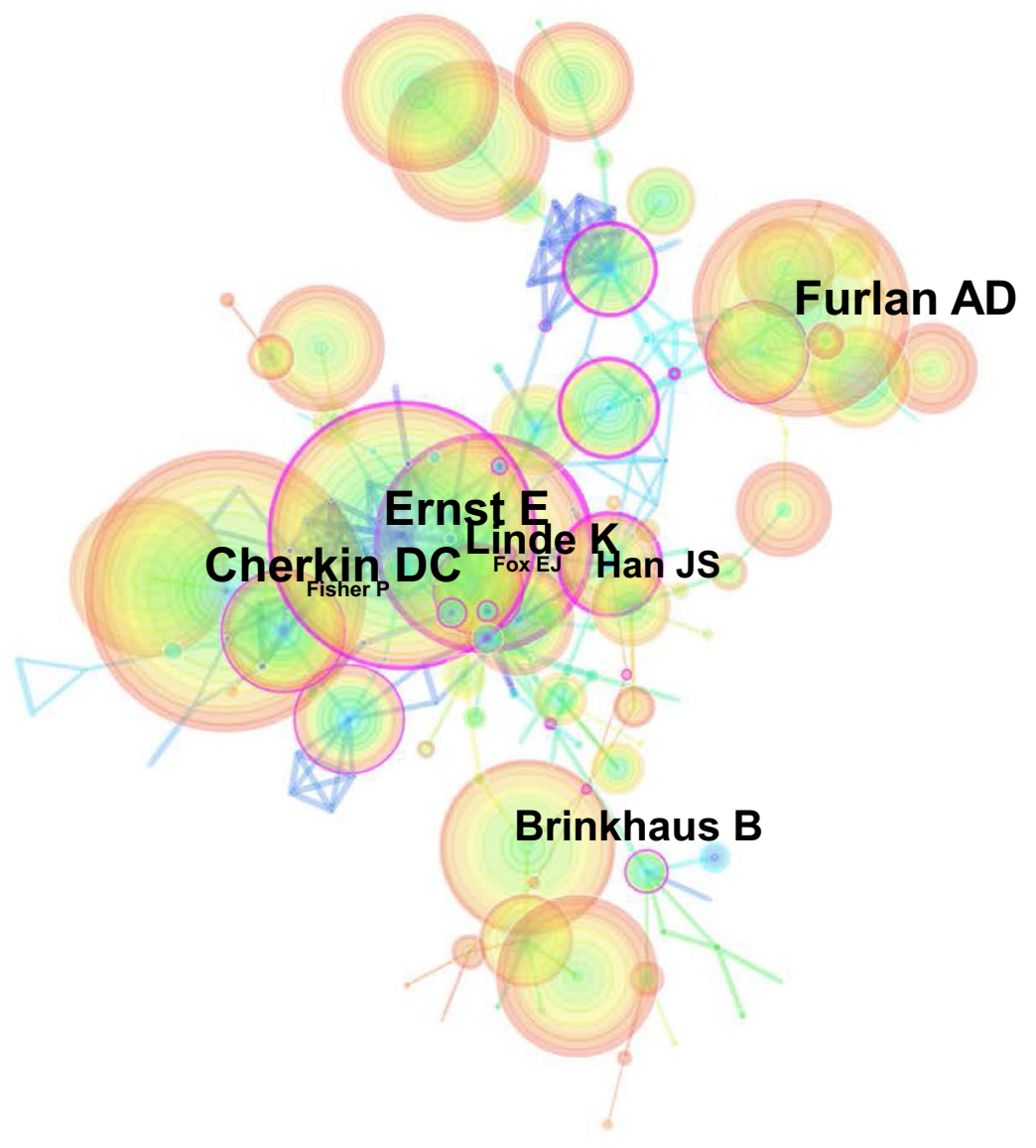

Figure 6 Author cocitation map related to acupuncture for LBP research from 1997 to 2016.

Abbreviation: LBP, low back pain.

Table 5 Top 10 active authors in acupuncture for LBP research ${ }^{a}$

\begin{tabular}{lllll}
\hline Ranking & Publications & Author & Ranking & Publications \\
\hline 1 & 29 & MacPherson & 6 & 23 \\
2 & 28 & Sherman & 7 & 19 \\
3 & 27 & Witt & 8 & 19 \\
4 & 25 & Cherkin & 9 & 16 \\
5 & 25 & Ernst & 10 & 14 \\
\hline
\end{tabular}

Notes: ${ }^{\mathrm{T}}$ The data has been taken from the publication year to retrieved date (November 26, 2016).

Abbreviation: LBP, low back pain. 
and self-care education. For example, one of his studies examined Traditional Chinese Medical (TCM) diagnoses and treatments for patients with chronic LBP and revealed that diversity in LBP makes it challenging to select a single treatment that has wide applicability. The study recommended that researchers attempt to develop a treatment that is considered credible by expert acupuncturists and has broad applicability to common clinical practice. ${ }^{29-33}$ Ernst is based at the University of Exeter (England) and studies acupuncture for LBP in terms of meta-analysis, critical analysis, and expert opinions. ${ }^{24,34,35}$ Linde is based at the Technical University of Munich (Germany) and studies acupuncture for LBP in terms of meta-analysis, the impact of patient expectations, and clinical and economic effectiveness. ${ }^{36-39}$

\section{Analysis of cocited references}

Generating a cited reference cocitation map resulted in 324 nodes and 555 links (Figure 7). An analysis in terms of cocitation counts and centrality (Tables 7 and 8 and Figure 7) revealed that the data on this topic over the past 20 years are generally in the form of 1) randomized trials, 2) comparisons with usual care, massage, sham acupuncture, or education,

Table 6 Top five cocited authors in acupuncture for LBP research in terms of cocitations and centrality

\begin{tabular}{lllll}
\hline Ranking & Cocitation counts & Cited author & Centrality & Cited author \\
\hline 1 & 246 & Cherkin & 0.42 & Linde \\
2 & 226 & Ernst & 0.39 & Ernst \\
3 & 186 & Furlan & 0.35 & Han \\
4 & 182 & Linde & 0.28 & Fox \\
5 & 152 & Brinkhaus & 0.27 & Fisher \\
\hline
\end{tabular}

Notes: ${ }^{\mathrm{a}}$ The data has been taken from the publication year to retrieved date (November 26, 2016).

Abbreviation: LBP, low back pain.

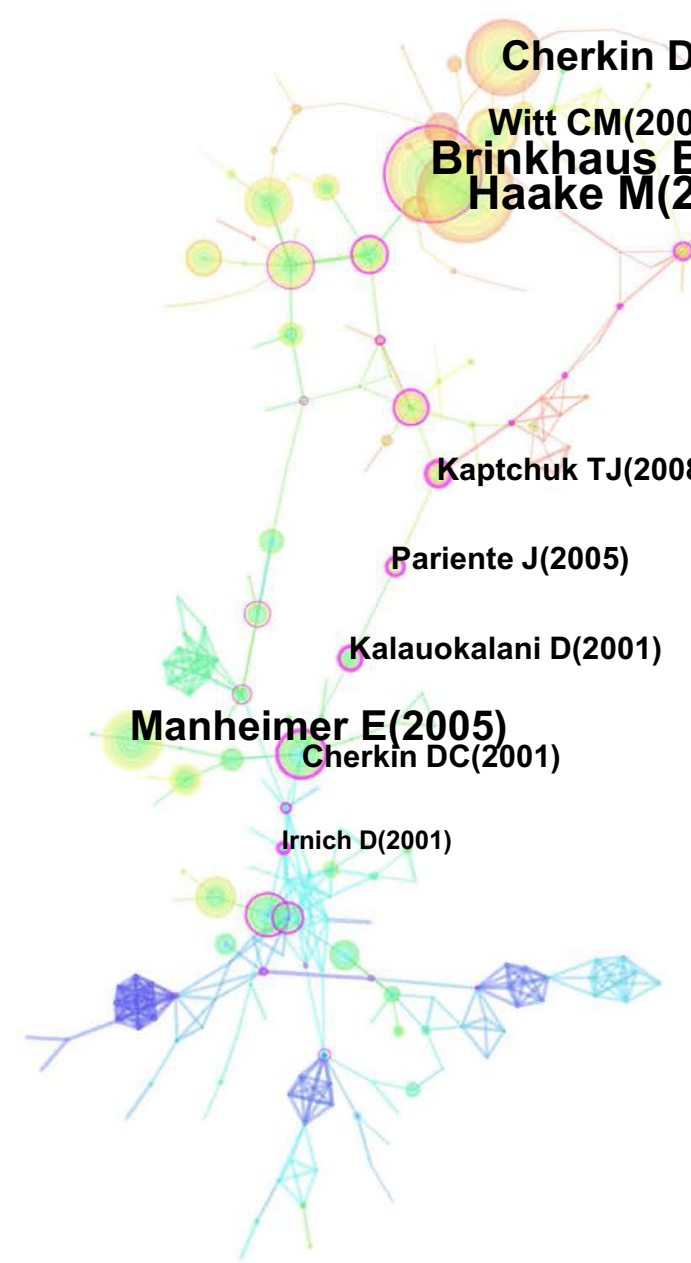

Figure 7 Reference cocitation map related to acupuncture for LBP research from 1997 to 2016 .

Abbreviation: LBP, low back pain. 
Table 7 Top five cocited references related to acupuncture for LBP research

\begin{tabular}{|c|c|c|c|}
\hline Ranking & Cocitation counts $^{a}$ & Cited reference & $\begin{array}{l}\text { Representative author } \\
\text { (publication year) }\end{array}$ \\
\hline I & 130 & $\begin{array}{l}\text { German acupuncture trials (GERAC) for chronic low back pain - randomized, } \\
\text { multicenter, blinded, parallel-group trial with } 3 \text { groups }\end{array}$ & Haake $(2007)^{52}$ \\
\hline 2 & 122 & $\begin{array}{l}\text { Acupuncture in patients with chronic low back pain - a randomized controlled } \\
\text { trial }\end{array}$ & Brinkhaus $(2006)^{53}$ \\
\hline 3 & 104 & $\begin{array}{l}\text { A randomized trial comparing acupuncture, simulated acupuncture, and usual } \\
\text { care for chronic low back pain }\end{array}$ & Cherkin $(2009)^{54}$ \\
\hline 4 & 82 & Meta-analysis: acupuncture for low back pain & Manheimer $(2005)^{55}$ \\
\hline 5 & 69 & $\begin{array}{l}\text { Pragmatic randomized trial evaluating the clinical and economic effectiveness } \\
\text { of acupuncture for chronic low back pain }\end{array}$ & Witt $(2006)^{56}$ \\
\hline
\end{tabular}

Notes: ${ }^{\text {TT }}$ The data has been taken from the publication year to retrieved date (November 26, 2016).

Abbreviation: LBP, low back pain.

Table 8 Top five cocited references in acupuncture for LBP research in terms of centrality

\begin{tabular}{|c|c|c|c|}
\hline Ranking & Centrality $^{a}$ & Cited reference & $\begin{array}{l}\text { Representative author } \\
\text { (publication year) }\end{array}$ \\
\hline I & 0.59 & $\begin{array}{l}\text { Randomized trial comparing traditional Chinese medical acupuncture, therapeutic } \\
\text { massage, and self-care education for chronic low back pain }\end{array}$ & Cherkin $(2001)^{57}$ \\
\hline 2 & 0.54 & $\begin{array}{l}\text { Components of placebo effect: randomised controlled trial in patients with irritable } \\
\text { bowel syndrome }\end{array}$ & Kaptchuk (2008) ${ }^{58}$ \\
\hline 3 & 0.51 & $\begin{array}{l}\text { Lessons from a trial of acupuncture and massage for low back pain - patient } \\
\text { expectations and treatment effects }\end{array}$ & Kalauokalani $(200 \mathrm{I})^{59}$ \\
\hline 4 & 0.51 & $\begin{array}{l}\text { Expectancy and belief modulate the neuronal substrates of pain treated by } \\
\text { acupuncture }\end{array}$ & Pariente $(2005)^{60}$ \\
\hline 5 & 0.50 & $\begin{array}{l}\text { Randomised trial of acupuncture compared with conventional massage and "sham" } \\
\text { laser acupuncture for treatment of chronic neck pain }\end{array}$ & Irnich $(2001)^{61}$ \\
\hline
\end{tabular}

Notes: ${ }^{\mathrm{T}}$ The data has been taken from the publication year to retrieved date (November 26, 2016).

Abbreviation: LBP, low back pain.

3) meta-analyses, 4) assessments of economic effectiveness, and 5) investigating placebo effects, including patient expectations and beliefs.

\section{Analysis of keyword cooccurrence and burst keywords}

Over time, a knowledge map of keyword cooccurrence could reflect hot topics, and burst keywords (keywords that are cited frequently over a period of time) could indicate frontier topics.

Generating a keyword cooccurrence map resulted in 165 nodes and 309 links (Figure 8). An analysis in terms of cooccurrence frequency and centrality (Table 9 and Figure 8) revealed that the hot keywords were randomized controlled trial, clinical trial, therapy, meta-analysis, alternative medicine, efficacy, placebo, follow-up, electroacupuncture, massage, quality, double blind, cost, and neck pain. There were four hot topics:

1. Research method: randomized controlled clinical trials are the most common and effective research method to prove the efficacy of acupuncture for LBP. However, it is not easy to enforce double blinding for both the acupuncturist and the subject. Many sham acupuncture methods are very controversial, and some research suggests that acupuncture might be effective because of the placebo effect (such as expectancy and belief). ${ }^{30,40,41}$

2. Evaluation: meta-analyses can evaluate the effectiveness of acupuncture in terms of effects on the quality of life, spinal flexion, pain intensity, and follow-up, when compared with no treatment or other treatments (usual care, transcutaneous electrical nerve stimulation, nonsteroidal anti-inflammatory drugs, muscle relaxants, analgesics, and sham acupuncture) in patients with LBP. However, the results are usually limited because of the low methodological quality of the studies or heterogeneity in the study characteristics. ${ }^{24,42,43}$ In addition, back pain can encompass neck pain and LBP, and while alternative medicines including acupuncture are commonly used to relieve back pain, some systematic reviews and meta-analyses are used to evaluate acupuncture for the treatment of neck pain or LBP. ${ }^{44,45}$

3. Economy: cost-effectiveness is an important criterion underpinning health care decisions. Acupuncture as 


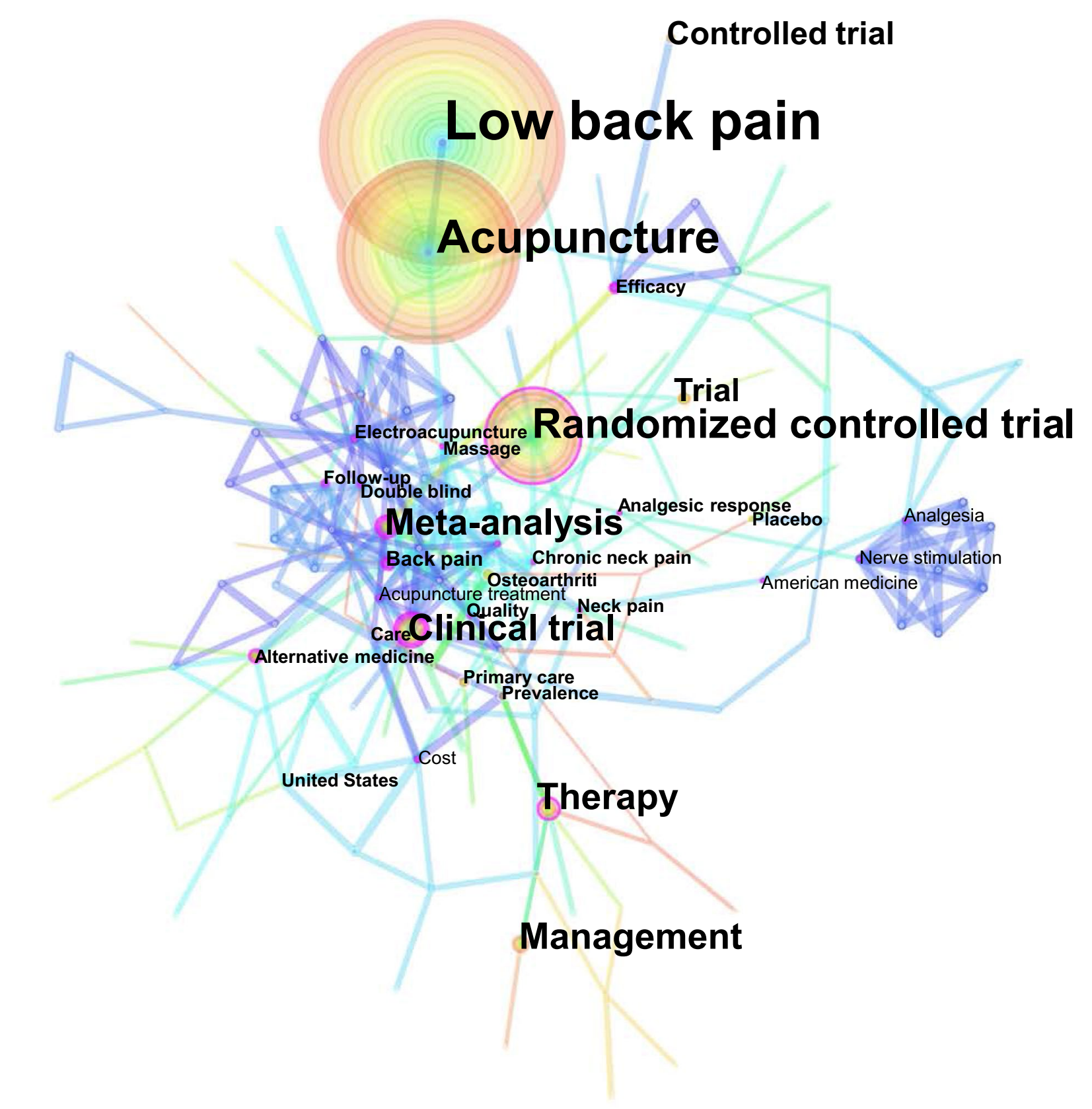

Figure 8 A keyword cooccurrence map of acupuncture for LBP from 1997 to 2016. Abbreviation: LBP, low back pain.

an alternative medicine has been increasingly used in patients with LBP and is expected to reduce costs. ${ }^{23,46-48}$

4. Comprehensive therapy: many alternative medical therapies, including massage, are combined with acupuncture to improve pain relief effects or as a control group to compare their effectiveness. ${ }^{30,33}$

So-called "burst words" represent words that are cited frequently over a period of time. CiteSpace was used to detect burst keywords, which are considered to be indicators of research frontier topics over time. As shown in
Figure 9, three frontiers in acupuncture for LBP were as follows:

1. Intervention: to compare acupuncture with other treatments as an intervention for LBP, in terms of disability improvement using controlled clinical trials.

2. Test reliability: to evaluate a questionnaire or scale to assess individuals' expectations. ${ }^{49,50}$

3. Prevalence: to estimate the prevalence of types of complementary and integrative health care, including acupuncture, for LBP patients. ${ }^{51}$ 
Table 9 Top 20 keywords in terms of frequency and centrality in acupuncture for LBP research

\begin{tabular}{lllll}
\hline Ranking & Frequency & Keyword & Centrality & Keyword \\
\hline 1 & 624 & Low back pain & 0.33 & Meta-analysis \\
2 & 498 & Acupuncture & 0.32 & Back pain \\
3 & 274 & Randomized controlled trial & 0.24 & Clinical trial \\
4 & 119 & Clinical trial & 0.22 & Efficacy \\
5 & 104 & Management & 0.2 & Electroacupuncture \\
6 & 103 & Therapy & 0.2 & Chronic neck pain \\
7 & 91 & Meta-analysis & 0.18 & Neck pain \\
8 & 78 & Controlled trial & 0.17 & Analgesic response \\
9 & 70 & Trial & 0.15 & Follow-up \\
10 & 66 & Care & 0.15 & Massage \\
11 & 65 & Alternative medicine & 0.14 & Therapy \\
12 & 62 & Osteoarthritis & 0.13 & Randomized controlled trial \\
13 & 61 & Placebo & 0.13 & Quality \\
14 & 59 & Electroacupuncture & 0.12 & Alternative medicine \\
15 & 59 & Follow-up & 0.12 & Acupuncture treatment \\
16 & 56 & Primary care & 0.12 & Cost \\
17 & 54 & Efficacy & 0.11 & Double blind \\
18 & 44 & Prevalence & 0.11 & Nerve stimulation \\
19 & 43 & Double blind & 0.11 & American medicine \\
20 & 42 & United States & 0.1 & Analgesia \\
\hline
\end{tabular}

Abbreviation: LBP, low back pain.

\section{Conclusion}

From the current bibliometric analysis of acupuncture for LBP publications over the previous 20 years, it was found that related publications increased at a rapid rate. In accordance with clinical practice guidelines from the USA, acupuncture for LBP was weak recommended in 2007, but moderate-quality evidence was reported in 2017, which revealed that acupuncture has been commonly used to relieve LBP disability. The USA, England, and Canada, with a high publication rate and centrality, were demonstrated to be the main research powers in this field, and all are developed countries, revealing that acupuncture as a complementary and alternative medicine is becoming more accepted by researchers. The strongest collaborations were identified between many developed countries and famous institutions, which are beneficial to the development of acupuncture for LBP. Although the average IF of the related journals is $<3$, some articles still received a large number of citations. A cross-sectional survey found that among patients who recently used acupuncture for pain relief, many suffered from LBP. Active authors from different countries and institutions have attempted to estimate and evaluate the effectiveness of acupuncture for LBP. To achieve this, they have performed randomized trials to compare acupuncture with usual care, massage, sham acupuncture, or education. Other research has involved meta-analyses and analyses of economic effectiveness. There has been a significant focus on the placebo effect, including patient expectations and beliefs. For example, a cost-effectiveness analysis inferred that acupuncture, in the management of persistent nonspecific LBP, seemed to be cost-effective in the longer term. A study concerning the treatment reactions of patients in an LBP trial showed that most patients reported relaxation and a willingness to try acupuncture again. ${ }^{28}$ However, TCM diagnoses and treatments for patients with chronic LBP are diverse, and this has emphasized the importance of developing treatments that are considered credible by expert acupuncturists. The development trends in the applications of acupuncture for LBP, as revealed by the hot topics and research frontiers discussed in this study, may help researchers to identify new directions with renewed focus.

In conclusion, this study provides an insight into acupuncture for LBP and valuable information for acupuncture researchers to identify new perspectives concerning potential collaborators and cooperative institutions, hot topics, and research frontiers.

\section{Acknowledgments}

The authors would like to express their appreciation to Professor CM Chen, who invented CiteSpace, which is free to use. This study was supported by the Guangdong Provincial Department of Science and Technology Project (2012A032500014). Yu-Dan Liang and Ying Li are the cofirst authors. 


\begin{tabular}{|c|c|c|c|c|c|}
\hline Keywords & Year & Strength & Begin & End & 1997-2016 \\
\hline Double blind & 1997 & 5.2727 & 1997 & 2009 & \\
\hline Spinal manipulation & 1997 & 5.0981 & 1997 & 2001 & \\
\hline Rheumatoid arthritis & 1997 & 4.9925 & 1997 & 2003 & \\
\hline Cost & 1997 & 4.307 & 1997 & 2005 & \\
\hline United States & 1997 & 3.7509 & 2000 & 2005 & \\
\hline Stimulation & 1997 & 3.7046 & 2000 & 2009 & \\
\hline Massage & 1997 & 7.7924 & 2002 & 2007 & \\
\hline Physical therapy & 1997 & 4.5062 & 2002 & 2010 & \\
\hline Chronic neck pain & 1997 & 3.7661 & 2002 & 2004 & \\
\hline Randomized clinical trial & 1997 & 3.4076 & 2002 & 2005 & \\
\hline Quality & 1997 & 3.2648 & 2002 & 2006 & \\
\hline Electrical nerve stimulation & 1997 & 9.6506 & 2003 & 2007 & \\
\hline Follow-up & 1997 & 9.3365 & 2003 & 2005 & \\
\hline Placebo controlled trial & 1997 & 7.5173 & 2004 & 2009 & \\
\hline Systematic review & 1997 & 5.7431 & 2005 & 2008 & \\
\hline Knee & Knee & 7.3257 & 2006 & 2012 & \\
\hline Migraine & 1997 & 6.5804 & 2006 & 2009 & \\
\hline Primary care & 1997 & 3.4739 & 2006 & 2008 & \\
\hline Cochrane collaboration & 1997 & 3.4648 & 2006 & 2007 & \\
\hline Complementary medicine & 1997 & 3.0713 & 2006 & 2008 & \\
\hline Placebo & 1997 & 7.3958 & 2007 & 2010 & \\
\hline National survey & 1997 & 4.2702 & 2007 & 2010 & \\
\hline Multicenter & 1997 & 3.7362 & 2008 & 2009 & \\
\hline Complementary & 1997 & 6.2354 & 2009 & 2013 & \\
\hline Diagnosis & 1997 & 3.683 & 2009 & 2011 & \\
\hline Expectation & 1997 & 3.1828 & 2010 & 2013 & \\
\hline Reliability & 1997 & 5.7756 & 2012 & 2016 & \\
\hline Mechanism & 1997 & 4.1169 & 2012 & 2014 & \\
\hline Disability & 1997 & 5.4892 & 2013 & 2016 & \\
\hline Chronic low back pain & 1997 & 3.7675 & 2013 & 2016 & \\
\hline Back pain & 1997 & 3.758 & 2013 & 2016 & \\
\hline Controlled clinical trial & 1997 & 3.5224 & 2013 & 2016 & \\
\hline Intervention & 1997 & 5.7181 & 2014 & 2016 & \\
\hline Prevalence & 1997 & 5.5535 & 2014 & 2016 & \\
\hline
\end{tabular}

Figure 9 Top 34 keywords with the strongest citation bursts.

Note: The red bars mean some keywords cited frequently; the green bars were keywords cited infrequently. 


\section{Author contributions}

YDL and YL collected the literature and wrote the article. $\mathrm{JZ}, \mathrm{XW}$, and $\mathrm{HZ}$ revised the article. YDL and XC designed the study and revised the article. All authors have read and approved the final article. All authors contributed toward data analysis, drafting and critically revising the paper and agree to be accountable for all aspects of the work.

\section{Disclosure}

The authors report no conflicts of interest in this work.

\section{References}

1. Hoy D, Bain C, Williams G, et al. A systematic review of the global prevalence of low back pain. Arthritis Rheum. 2012;64(6):2028-2037.

2. Yang H, Haldeman S, Lu ML, Baker D. Low back pain prevalence and related workplace psychosocial risk factors: a study using data from the 2010 National Health Interview Survey. J Manipulative Physiol Ther. 2016;39(7):459-472.

3. Maher C, Underwood M, Buchbinder R. Non-specific low back pain. Lancet. 2017;389(10070):736-747.

4. Luo X, Pietrobon R, Sun SX, Liu GG, Hey L. Estimates and patterns of direct health care expenditures among individuals with back pain in the United States. Spine. 2004;29(1):79-86.

5. Martin BI, Deyo RA, Mirza SK, et al. Expenditures and health status among adults with back and neck problems. JAMA. 2008;299(6):656-664

6. Nahin RL, Boineau R, Khalsa PS, Stussman BJ, Weber WJ. Evidencebased evaluation of complementary health approaches for pain management in the United States. Mayo Clin Proc. 2016;91(9):1292-1306.

7. Bishop A, Holden MA, Ogollah RO, Foster NE; EASE Back Study Team. Current management of pregnancy-related low back pain: a national cross-sectional survey of U.K. physiotherapists. Physiotherapy. 2016; 102(1):78-85.

8. Shin JS, Ha IH, Lee J, et al. Effects of motion style acupuncture treatment in acute low back pain patients with severe disability: a multicenter, randomized, controlled, comparative effectiveness trial. Pain. 2013;154(7):1030-1037.

9. Li J, Zhang JH, Yi T, Tang WJ, Wang SW, Dong JC. Acupuncture treatment of chronic low back pain reverses an abnormal brain default mode network in correlation with clinical pain relief. Acupunct Med. 2014; 32(2):102-108.

10. Chen D, Liu Z, Luo Z, Webber M, Chen J. Bibliometric and visualized analysis of emergy research. Ecol Eng. 2016;90:285-293.

11. Ma R, Ho Y-S. Comparison of environmental laws publications in Science Citation Index Expanded and Social Science Index: a bibliometric analysis. Scientometrics. 2016;109(1):227-239.

12. Leefmann J, Levallois C, Hildt E. Neuroethics 1995-2012. A bibliometric analysis of the guiding themes of an emerging research field. Front Hum Neurosci. 2016;10:336.

13. Han JS, Ho YS. Global trends and performances of acupuncture research. Neurosci Biobehav Rev. 2011;35(3):680-687.

14. More AO, Tesser CD, da Silva JB, Min LS. Status and impact of acupuncture research: a bibliometric analysis of Global and Brazilian Scientific Output from 2000 to 2014. J Altern Complement Med. 2016;22(6): 429-436.

15. Chen CM. CiteSpace II: detecting and visualizing emerging trends and transient patterns in scientific literature. J Am Soc Inf Sci Technol. 2006;57(3):359-377.

16. Liu Z, Yin Y, Liu W, Dunford M. Visualizing the intellectual structure and evolution of innovation systems research: a bibliometric analysis. Scientometrics. 2015;103(1):135-158.

17. Chen CM. The centrality of pivotal points in the evolution of scientific networks. In: IUI'05 Proceedings of the $10^{\text {th }}$ International Conference on Intelligent User Interfaces; January 10-13, 2005; San Diego, CA. New York, NY: ACM; 2005.
18. Xie P. Study of international anticancer research trends via co-word and document co-citation visualization analysis. Scientometrics. 2015; 105(1):611-622.

19. Breivik H, Collett B, Ventafridda V, Cohen R, Gallacher D. Survey of chronic pain in Europe: prevalence, impact on daily life, and treatment. Eur J Pain. 2006;10(4):287-333.

20. Chou R, Qaseem A, Snow V, et al; Clinical Efficacy Assessment Subcommittee of the American College of Physicians; American College of Physicians; American Pain Society Low Back Pain Guidelines Panel. Diagnosis and treatment of low back pain: a joint clinical practice guideline from the American College of Physicians and the American Pain Society. Ann Intern Med. 2007;147(7):478-491.

21. Qaseem A, Wilt TJ, McLean RM, Forciea MA; Clinical Guidelines Committee of the American College of Physicians. Noninvasive treatments for acute, subacute, and chronic low back pain: a clinical practice guideline from the American College of Physicians. Ann Intern Med. Epub 2017 Feb 14.

22. Burke A, Upchurch DM, Dye C, Chyu L. Acupuncture use in the United States: findings from the National Health Interview Survey. J Altern Complement Med. 2006;12(7):639-648.

23. Ratcliffe J, Thomas KJ, MacPherson H, Brazier J. A randomised controlled trial of acupuncture care for persistent low back pain: cost effectiveness analysis. Br Med J. 2006;333(7569):626A-628A.

24. Manheimer E, White A, Berman B, Forys K, Ernst E. Meta-analysis: acupuncture for low back pain. Ann Intern Med. 2005;142(8):651-663.

25. MacPherson H, Thorpe L, Thomas K, Campbell M. Acupuncture for low back pain: traditional diagnosis and treatment of 148 patients in a clinical trial. Complement Ther Med. 2004;12(1):38-44.

26. Thomas KJ, MacPherson H, Ratcliffe J, et al. Longer term clinical and economic benefits of offering acupuncture care to patients with chronic low back pain. Health Technol Assess. 2005;9(32):iii-iv,ix-x,1-109.

27. Thomas KJ, MacPherson H, Thorpe L, et al. Randomised controlled trial of a short course of traditional acupuncture compared with usual care for persistent non-specific low back pain. Br Med J. 2006; 333(7569):623-626.

28. Hopton AK, Thomas KJ, MacPherson H. Willingness to try acupuncture again: reports from patients on their treatment reactions in a low back pain trial. Acupunct Med. 2010;28(4):185-188.

29. Cherkin DC, Sherman KJ, Hogeboom CJ, et al. Efficacy of acupuncture for chronic low back pain: protocol for a randomized controlled trial. Trials. 2008;9:11.

30. Kalauokalani D, Cherkin DC, Sherman KJ, Koepsell TD, Deyo RA. Lessons from a trial of acupuncture and massage for low back pain - patient expectations and treatment effects. Spine. 2001;26(13):1418-1424.

31. Cherkin DC, Sherman KJ, Avins AL, et al. A randomized trial comparing acupuncture, simulated acupuncture, and usual care for chronic low back pain. Arch Intern Med. 2009;169(9):858-866.

32. Sherman KJ, Cherkin DC, Hogeboom CJ. The diagnosis and treatment of patients with chronic low-back pain by traditional Chinese medical acupuncturists. J Altern Complement Med. 2001;7(6):641-650.

33. Cherkin DC, Eisenberg D, Sherman KJ, et al. Randomized trial comparing traditional Chinese medical acupuncture, therapeutic massage, and self-care education for chronic low back pain. Arch Intern Med. 2001;161(8):1081-1088.

34. Ernst E. Acupuncture - a critical analysis. J Intern Med. 2006;259(2): 125-137.

35. Ernst E, Pittler MH. Experts' opinions on complementary/alternative therapies for low back pain. J Manipulative Physiol Ther. 1999; 22(2):87-90.

36. Vickers AJ, Cronin AM, Maschino AC, et al; Acupuncture Trialists' Collaboration. Acupuncture for chronic pain individual patient data meta-analysis. Arch Intern Med. 2012;172(19):1444-1453.

37. Linde K, Witt CM, Streng A, et al. The impact of patient expectations on outcomes in four randomized controlled trials of acupuncture in patients with chronic pain. Pain. 2007;128(3):264-271.

38. Brinkhaus $\mathrm{B}$, Witt CM, Jena $\mathrm{S}$, et al. Acupuncture in patients with chronic low back pain - a randomized controlled trial. Arch Intern Med. 2006; 166(4):450-457. 
39. Witt CM, Jena S, Selim D, et al. Pragmatic randomized trial evaluating the clinical and economic effectiveness of acupuncture for chronic low back pain. Am J Epidemiol. 2006;164(5):487-496.

40. Hasegawa TM, Baptista AS, de Souza MC, Yoshizumi AM, Natour J. Acupuncture for acute non-specific low back pain: a randomised, controlled, double-blind, placebo trial. Acupunct Med. 2014;32(2):109-115.

41. Pariente J, White P, Frackowiak RSJ, Lewith G. Expectancy and belief modulate the neuronal substrates of pain treated by acupuncture. $\mathrm{Neu}$ roimage. 2005;25(4):1161-1167.

42. Lam M, Galvin R, Curry P. Effectiveness of acupuncture for nonspecific chronic low back pain: a systematic review and meta-analysis. Spine. 2013;38(24):2124-2138.

43. Xu M, Yan S, Yin X, et al. Acupuncture for chronic low back pain in long-term follow-up: a meta-analysis of 13 randomized controlled trials. Am J Chin Med. 2013;41(1):1-19.

44. Furlan AD, Yazdi F, Tsertsvadze A, et al. A systematic review and meta-analysis of efficacy, cost-effectiveness, and safety of selected complementary and alternative medicine for neck and low-back pain. Evid Based Complement Alternat Med. 2012;2012:61.

45. Yuan QL, Guo TM, Liu L, Sun F, Zhang YG. Traditional Chinese medicine for neck pain and low back pain: a systematic review and meta-analysis. PLoS One. 2015;10(2):37.

46. Kim N, Yang B, Lee T, Kwon S. An economic analysis of usual care and acupuncture collaborative treatment on chronic low back pain: a Markov model decision analysis. BMC Complement Altern Med. 2010;10:74.

47. Moritz S, Liu MF, Rickhi B, Xu TJ, Paccagnan P, Quan HD. Reduced health resource use after acupuncture for low-back pain. J Altern Complement Med. 2011;17(11):1015-1019.

48. Witt CM, Pach D, Reinhold T, et al. Treatment of the adverse effects from acupuncture and their economic impact: a prospective study in 73,406 patients with low back or neck pain. Eur J Pain. 2011;15(2):193-197.

49. Jones SMW, Lange J, Turner J, et al. Development and validation of the EXPECT Questionnaire: assessing patient expectations of outcomes of complementary and alternative medicine treatments for chronic pain. J Altern Complement Med. 2016;22(11):936-946.

50. Kim YJ, Lee IS, Kim HS, et al. Validation of the Korean version of the Acupuncture Expectancy Scale. Acupunct Med. 2014;32(1):51-55.
51. Rhee TG, Leininger BD, Ghildayal N, Evans RL, Dusek JA, Johnson PJ. Complementary and integrative healthcare for patients with mechanical low back pain in a US hospital setting. Complement Ther Med. 2016;24:7-12.

52. Haake M, Müller HH, Schade-Brittinger C, et al. German Acupuncture Trials (GERAC) for chronic low back pain: randomized, multicenter, blinded, parallel-group trial with 3 groups. Arch Intern Med. 2007; 167(17):1892-1898.

53. Brinkhaus B, Witt CM, Jena S, et al. Acupuncture in patients with chronic low back pain: a randomized controlled trial. Arch Intern Med. 2006;166(4):450-457.

54. Cherkin DC, Sherman KJ, Avins AL, et al. A randomized trial comparing acupuncture, simulated acupuncture, and usual care for chronic low back pain. Arch Intern Med. ;169(9):858-866.

55. Manheimer E, White A, Berman B, Forys K, Ernst E. Meta-analysis: acupuncture for low back pain. Ann Intern Med. 2005;142(8):651-663.

56. Witt CM, Jena S, Selim D, et al. Pragmatic randomized trial evaluating the clinical and economic effectiveness of acupuncture for chronic low back pain. Am J Epidemiol. 2006;164(5):487-496.

57. Cherkin DC, Eisenberg D, Sherman KJ, et al. Randomized trial comparing traditional Chinese medical acupuncture, therapeutic massage, and self-care education for chronic low back pain. Arch Intern Med. 2001;161(8):1081-1088.

58. Kaptchuk TJ, Kelley JM, Conboy LA, et al. Components of placebo effect: randomised controlled trial in patients with irritable bowel syndrome. BMJ. 2008;336(7651):999-1003.

59. Kalauokalani D, Cherkin DC, Sherman KJ, Koepsell TD, Deyo RA. Lessons from a trial of acupuncture and massage for low back pain: patient expectations and treatment effects. Spine (Phila Pa 1976). 2001; 26(13):1418-1424.

60. Pariente J, White P, Frackowiak RS, Lewith G. Expectancy and belief modulate the neuronal substrates of pain treated by acupuncture. Neuroimage. 2005;25(4):1161-1167.

61. Irnich D, Behrens N, Molzen H, et al. Randomised trial of acupuncture compared with conventional massage and "sham" laser acupuncture for treatment of chronic neck pain. BMJ. 2001;322(7302): 1574-1578.
Journal of Pain Research

\section{Publish your work in this journal}

The Journal of Pain Research is an international, peer reviewed, open access, online journal that welcomes laboratory and clinical findings in the fields of pain research and the prevention and management of pain. Original research, reviews, symposium reports, hypothesis formation and commentaries are all considered for publication.

\section{Dovepress}

The manuscript management system is completely online and includes a very quick and fair peer-review system, which is all easy to use. Visit http://www.dovepress.com/testimonials.php to read real quotes from published authors. 